\title{
Effectiveness of a decontamination method for donor corneas
}

\author{
P R BADENOCH, S J ALFRICH, T R WEDDING, AND D J COSTER \\ From the Department of Ophthalmology, Flinders Medical Centre, Bedford Park, South Australia 5042
}

SUMMARY A retrospective study was made of the effectiveness of an eye bank decontamination and storage method. A comparison was made between microbial cultures taken from the limbus at enucleation and from scleral remnants recovered after surgery. Organisms were isolated from the limbus of $73 \%$ of donor eyes and from $4 \%$ of remnants. Standard eye bank procedures were found to eradicate gut and skin organisms, including candida, from donor tissue.

Postoperative endophthalmitis is an infrequent yet serious complication of penetrating keratoplasty. A survey by Leveille et al. found a $0 \cdot 2 \%$ incidence of infectious endophthalmitis in the early postoperative period.' Although not all such cases are attributable to contamination of the donor tissue or storage medium, ${ }^{2}$ there are numerous reports of cases in which bacteria, fungi, or viruses have been transferred from donor to host. ${ }^{13}$ Furthermore, the move towards extended storage of donor corneas may exacerbate the problem of microbial contamination. Careful microbiological assessment of graft material is therefore a primary function of an eye bank.

Since its establishment in 1983 the Lions Eye Bank of South Australia has collected approximately 500 pairs of eyes for distribution within the State and beyond. To determine the effectiveness of the decontamination and storage procedures used we have compared the limbal flora at enucleation with the culture results of the retrievable scleral remnants and noted the progress of the patients postoperatively.

\section{Materials and methods}

Eyes were collected between one and 12 hours after death (mean 4.5 hours). Most were removed and processed by either of two trained eye bank technicians, but in some cases a medical graduate made the collection.

Prior to enucleation the eyelashes, eyelids, and skin in the vicinity of the eye were swabbed with a $1 \%$

Correspondence to Professor D J Coster, Department of Ophthalmology, Flinders Medical Centre, Bedford Park, South Australia 5042 . iodine solution (Povidone-Iodine). A lid speculum was then inserted and a limbal swab was taken, plated onto horse blood agar, and placed in brain-heart infusion broth (BHIB). The eye was irrigated with $15 \mathrm{ml}$ of normal saline and then removed by an aseptic technique. The globe was placed in a glass pot containing gauze moistened with saline and 10 drops of Neosporin (polymyxin B, neomycin, and gramicidin) were applied to the cornea. The eye was transported to the Eye Bank for slit-lamp examination and processing.

Working in a laminar-flow hood the technician soaked the globe for 3 minutes in $40 \mathrm{ml}$ of $1 \%$ iodine and rinsed in normal saline. The corneoscleral button was removed by aseptic techniques and was placed in a sterile polypropylene storage chamber (CooperVision Inc., Irvine, California) with McCarey-Kaufman (MK) medium containing $60 \mathrm{mg} / \mathrm{l}$ gentamicin sulphate. It was refrigerated at $4^{\circ} \mathrm{C}$ until required.

The remnants of the buttons used within the parent institution (Flinders Medical Centre) were recovered for microbiological analysis. Scleral rims were divided and each half was put in a tube of thioglycollate broth. One of each pair of thioglycollate broths was incubated anaerobically.

All the media were incubated for two days at $37^{\circ} \mathrm{C}$ in $5 \% \quad \mathrm{CO}_{2} /$ air. Organisms were identified by standard methods as given by Lennette et al. ${ }^{5}$ and the surgeon was informed of any growth from scleral remnants.

A total of 434 pairs of eyes were collected during the study period. Limbal swabs were taken from both eyes of 278 donors and from one eye of 33 donors, 
giving a total of 589 eyes swabbed. Eyes removed by medical staff at other hospitals did not always have limbal swabs taken.

\section{Results}

Micro-organisms were isolated from $73 \%$ of the limbal swabs. The list of organisms cultured (Table 1) is dominated by Gram-positive skin flora and Gramnegative gut bacteria. Of the donors who had both eyes swabbed $19 \%$ had organisms cultured from one eye only while $63 \%$ were positive for both eyes. Of the culture-positive eyes $35 \%$ gave a mixed growth, and in $24 \%$ growth occurred only in BHIB. Besides those seen on the blood plate additional species of organisms grew in the broth in the case of $3 \%$ of the culture-positive eyes.

Of 67 scleral remnants 64 were culture-negative. Of the latter, 50 had limbal swabs taken at enuclea-

Table 1 Micro-organisms isolated from limbal swabs

\begin{tabular}{ll}
\hline Micro-organisms & $\begin{array}{l}\text { Percentage of } \\
\text { eyes positive }\end{array}$ \\
\hline Staphylococcus epidermidis & $50 \cdot 6$ \\
viridans streptococi & $17 \cdot 0$ \\
Corynebacterium spp. & $10 \cdot 0$ \\
Staphylococcus aureus & $9 \cdot 7$ \\
Proteus spp. & $2 \cdot 5$ \\
Pseudomonas spp. & $1 \cdot 9$ \\
Bacillus spp. & $1 \cdot 7$ \\
Enterobacter spp. & $1 \cdot 2$ \\
$\beta$-Haemolytic streptococci & $0 \cdot 8$ \\
Escherichia coli & $0 \cdot 8$ \\
Streptococcus faecalis & $0 \cdot 5$ \\
Micrococcus spp. & $0 \cdot 5$ \\
Candida albicans & $0 \cdot 5$ \\
Acinetobacter calcoaceticus & $0 \cdot 3$ \\
Klebsiella oxytoca & $0 \cdot 3$ \\
Salmonella spp. & $0 \cdot 3$ \\
Haemophilus influenzae & $0 \cdot 2$ \\
Neisseria sp. & $0 \cdot 2$ \\
Moraxella sp. & $0 \cdot 2$ \\
Streptococus pneumoniae & $0 \cdot 2$ \\
\hline
\end{tabular}

Table 2 Elimination of micro-organisms from donor eyes

\begin{tabular}{ll}
\hline Micro-organisms from limbal swabs & $\begin{array}{l}\text { No. of negative scleral } \\
\text { remnant cultures }\end{array}$ \\
\hline Staphylococcus epidermidis & 33 \\
viridans streptococci & 11 \\
Staphylococcus aureus & 9 \\
Corynebacterium spp. & 8 \\
Proteus spp. & 2 \\
Klebsiella oxytoca & 1 \\
Enterobacter cloacea & 1 \\
Escherichia coli & 1 \\
B-Haemolytic Streptococcus & 1 \\
Bacillus sp. & 1 \\
Candida albicans & 1 \\
\hline
\end{tabular}

tion, resulting in 43 positive cultures. The organisms present in these cultures (Table 2) were those that were subsequently eliminated from the donor tissue during the disinfection and storage procedures. The bacteria that most commonly contaminated the donor limbus, namely, staphylococci, streptococci, and coryneforms, were shown to be removed with similar efficiency. Candida was also eliminated in one case.

Two rims grew Staphylococcus epidermidis; one eye was culture-negative from the limbus and the other had grown Staph. epidermidis. A third rim grew Proteus mirabilis and Staph. epidermidis; no limbal swab had been taken from this eye. There were no cases of postoperative endophthalmitis involving graft material obtained from the Eye Bank.

\section{Discussion}

Most donor eyes harbour micro-organisms prior to processing and storage. In this study the organisms were isolated from $73 \%$ of donor eyes, and positivity rates of $86 \%,{ }^{\circ} 100 \%,{ }^{7}$ and $82 \%{ }^{8}$ have been reported by others. Polack et al. ${ }^{7}$ compared the organisms isolated from donor eyes with those from living people and found a marked increase in the incidence of enteric Gram-negative bacilli recovered post mortem. ${ }^{7}$ Similarly, we have found an increasing occurrence of these bacteria from $2.6 \%$ in living people (unpublished data) to $7 \cdot 2 \%$ in donor eyes. This is probably associated with the frequency with which necropsy precedes enucleation (in approximately $60 \%$ of cases in the study by Polack et al. ${ }^{7}$ and in $10 \%$ of cases here) or the time lapse between death and eye collection.

We have shown that a number of common skin and gut organisms are eradicated from donor tissue by standard eye bank procedures. On the basis of invitro susceptibility tests we assume that gentamicin has contributed to the removal of staphylococci, coryneforms, Bacillus spp., and Enterobacteriaceae, ${ }^{9}$ that polymyxin B has been effective against the Enterobacteriaceae except for proteus, that neomycin has been effective against staphylococci and Enterobacteriaceae, and that gramicidin has been effective against Gram-positive bacteria, including streptococci. It is important to allow donor corneas to soak in MK-gentamicin solution for an hour or more at room temperature before refrigeration or surgery because gentamicin has been shown to be more effective at $23^{\circ} \mathrm{C}$ than at $4^{\circ} \mathrm{C}$."'

Presumably the elimination of candida from a donor eye was due either to the soaking in iodine or the saline irrigation. Irrigation alone has been shown to reduce markedly the incidence of contamination of donor eyes" and to decrease the number of bacteria 
recoverable from the cornea in an animal model. ${ }^{12}$ The low incidence of fungal contamination of donor eyes in the present study is probably related to the dry, temperate climate of South Australia. An eye bank in a tropical climate would need to consider adding a fungicidal agent to the decontamination and storage procedures.

Organisms were cultured from the scleral remnants of three eyes, but fortunately no infections occurred postoperatively. The case where staphylococci grew from the remnant but no growth occurred from the donor limbal swab is of doubtful significance. The other two cases, in which staphylococci and proteus had most likely survived the decontamination procedures, are more worrying. Broad-spectrum antibiotics given topically to all patients after transplantation may have saved these eyes from becoming infected.

Recently we have begun swabbing donor eyes for culture after they have been soaked in iodine and immediately before the corneoscleral button is removed. This will establish the importance of the procedure involving irrigation, Neosporin, and iodine as against the subsequent procedure of storage in MK medium plus gentamicin. It will also alert us to the passage of fungi or gentamicin-resistant bacteria such as anaerobes and some of the streptococci. About 50 such swabs have been taken so far and no organisms have been detected.

We do not collect tissue for the eye bank from people who have died of infectious diseases. This may be conservative practice, since, for example, no correlation has been found between bacteraemia and ocular contamination, ${ }^{13}$ but newly established eye banks need to adopt a cautious approach. As a further precaution blood from all donors is tested for hepatitis $B$ virus surface antigen and for antibodies to human immunodeficiency virus.

The establishment of effective decontamination methods for donor eyes has been central to the success rate now associated with corneal transplantation. Of equal importance is the need for eye bank personnel to be aware of the potential dangers presented by even a small number of organisms and for them to be well educated in basic microbiological techniques.

The authors thank Judy Stone for manuscript preparation and Leo Joseph and Wendy Laffer for editorial assistance.

\section{References}

1 Leveille AS, McMullan FD, Cavanagh HD. Endophthalmitis following penetrating keratoplasty. Ophthalmology 1983; 90: 38-9.

2 Guss RB, Koenig S, De La Pena W, Marx M, Kaufman HE. Endophthalmitis after penetrating keratoplasty. $\mathrm{Am} J$ Ophthalmol 1983; 95: 651-8.

3 Gandhi S, Lamberts D, Perry H. Donor-to-host transmission of disease via corneal transplantation. Surv Ophthalmol 1981; 25: 306-11.

4 Insler MS, Cavanagh HD, Wilson LA. Gentamicin-resistant Pseudomonas endophthalmitis after penetrating keratoplasty. BrJ Ophthalmol 1985; 69: 189-91.

5 Lennette EH, Balows A, Hausler WJ, Shadomy HJ, eds. Manual of clinical microbiology. Washington, DC: American Society for Microbiology, 1985.

6 Boberg-Ans J, Badsberg E, Rasmussen J. Frequency of infection in donor eyes post mortem. BrJ Ophthalmol 1962; 46: 365-8.

7 Polack FM, Locatcher-Khorazo D, Gutierrez E. Bacteriologic study of 'donor' eyes. Arch Ophthalmol 1967; 78: 219-25.

8 Schimmelpfennig B, Hurzeler R. Bacterial flora of stored human donor corneas after antibiotic treatment. Graefes Arch Clin Exp Ophthalmol 1977; 202: 181-5.

9 Kucers A, Bennett NMcK. The use of antibiotics. 3rd ed. London: Heinemann, 1979.

10 Baum J, Barza M, Kane A. Efficacy of penicillin G, cefazolin, and gentamicin in M-K medium at $4^{\circ} \mathrm{C}$. Arch Ophthalmol 1978; 96: 1262-4.

11 Pardos GJ, Gallagher MA. Microbial contamination of donor eyes. Arch Ophthalmol 1982; 100: 1611-3.

12 Goldman KN, Centifanto Y, Kaufman HE, Slappey TE. Prevention of surface bacterial contamination of donor corneas. Arch Ophthalmol 1978; 96: 2277-80.

13 Clark WM, Heaton KT, Snider GR, Reeve RB, Caskey PJ, Olson RJ. Donor eye contamination. Am J Ophthalmol 1982; 94: 395-7.

Accepted for publication 27 January 1987. 